\title{
Novos possíveis para a militância no campo da Saúde: a afirmação de desvios nos encontros entre trabalhadores, gestores e usuários do SUS
}

\author{
Gustavo Nunes de Oliveira ${ }^{1}$ \\ Ricardo Sparapan Pena ${ }^{2}$ \\ Simone Cristina de Amorim ${ }^{3}$ \\ Sergio Resende Carvalho ${ }^{4}$ \\ Bruno Mariani de Souza Azevedo ${ }^{5}$ \\ Anderson Luiz Barbosa Martins ${ }^{6}$ \\ Maíra Barros Guerra7
}

OLIVEIRA, G.N. et al. New possibilities for militancy in the field of healthcare:

affirmation of deviations in encounters among SUS workers, managers and users.

Interface - Comunic., Saude, Educ., v.13, supl.1, p.523-9, 2009.

The authors make comments about militancy in the field of healthcare, especially for defending the Brazilian Unified Health System (SUS) as a universal public policy. After indicating some strategies for such militancy, the text discusses centralism and the identifying nature of these practices. It highlights and questions four forms of centralism: the "common good" in its representations; procedures as offers of health technologies; users and notions about their needs/demands; and careless protection of life. As an alternative, the authors propose a new form of militancy within SUS, as intensive practice produced at the meeting point within the dimension of the relationship between managers, workers and users.

Keywords: Health system. Healthcare policy. Public health. Ethics. Production of subjectivity.
Os autores tecem considerações sobre a militância no campo da saúde, em especial na defesa do Sistema Único de Saúde (SUS), enquanto uma política pública universal. Após apontar algumas estratégias desta militância, o texto discute o centralismo e o caráter identitário dessas práticas. Destacam e problematizam quatro formas de centralismo: do "bem comum" em suas representações; o procedimento como oferta de tecnologias de saúde; do usuário e as concepções sobre suas necessidades/demandas; e da proteção inadvertida da vida. Propõem, como alternativa, uma nova militância no SUS, como prática intensiva e produzida no encontro, na dimensão relacional, entre gestores, trabalhadores e usuários.

Palavras-chave: Sistema Único de Saúde. Política de saúde. Saúde pública. Ética. Produção de subjetividade.

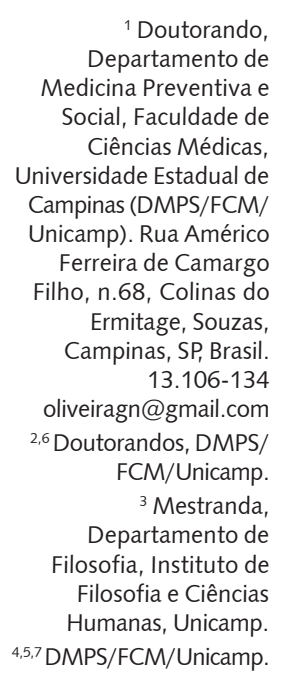




\section{Introdução}

Quando evocamos a imagem de um militante, quem facilmente nos vem ao pensamento é alguém de fala firme e disposto ao sacrifício por uma causa. Frequentemente visto em manifestações, em cima de um caixote, aos berros, ou em um palanque empunhando um megafone, ou mesmo distribuindo panfletos com dizeres que se destinem a subverter algo. Algo este que encontra em sua voz um gritar que capta as supersonias abafadas das gargantas de multidões que, sem saber onde gritar, "engolem", no cotidiano, as dores resignadas de tudo aquilo que, em nome da sobrevivência, foi-lhes enfiado goela abaixo. Este militante é dos poucos que reconhece uma dor que põe em risco o que estava ali vivo, embora frágil e anestesiado.

Vemos que, frequentemente, é posto em cena um militante/mártir disposto até mesmo a morrer em nome de seus ideais. Para este militante, a bandeira que carrega confunde-se com o que ele acredita ser e, muitas vezes, não vê que a bandeira que tanto ostenta acabou sendo, aos poucos, 'transplantada' para a sua córnea. Então, para onde ele mira o olhar, só vê a bandeira e, por isso, deixa de enxergar o que se põe diante de seus olhos.

Nesta militância há um finalismo totalitário, no qual o ideal em cisão com a prática é, frequentemente, posto como um fim a que se pretende chegar. A existência deste fim, alardeada no discurso do militante de sua bandeira/identidade, choca-se contra a bandeira de outro militante, que em uma guerrilha discursiva se põe a atacar o outro, combater o outro, tentando queimar a outra bandeira; necessita que o outro seja o mau para poder sentir-se o bom, o elevado, o justo (Nietzsche, 1998). Muitas vezes, os que não estão no foco do poder instituído acusam os que estão; por sua vez, os que estão acusam aqueles de não fazerem nada. E vai por aí a sucessão de acusações: eles, os que detêm o poder; eles, os teóricos; eles, os que só fazem práticas sem consistência teórica; eles, os que não têm cuidado com a vida; eles, os que não se importam; eles, os ativistas; eles, os que não refletem sobre o que fazem; eles, eles, eles... Acusação como estratégia para mostrar o nosso serviço, a nossa bandeira, a nossa militância/identidade como sendo a única legítima, modelo que deveria ser sempre copiado, porque se todos fossem como nós, aí sim tudo seria bom. Porque nós, sim, somos os revolucionários, nós, sim, fazemos um bom trabalho; a revolução deles não nos serve. E aí os encontros são impossibilitados, perdem sua potência transformadora, pois ora, o que vem deles é por nós negado. Essa "imagem" continua funcionando como uma das referências do que seja o agir militante.

Exprime-se aqui um militante que pleiteia uma hegemonia na qual as relações que ocorrem são, antes de tudo, relações de dominação, uma vez que a validade do discurso do outro não é reconhecida. Este militante cobra do outro conscientizar-se de quão exemplar e bom é o mundo que ele propõe. Conscientizar, aqui, pode ser reduzido a aderir a um (mundo) "proposto". Deste modo, esta militância se origina a partir de uma identidade afirmadora de certa forma de viver e de estar no mundo, baseando-se em representações sobre uma - ou qualquer - causa, constituindo-se como centralidade inquestionável, estanque. A reprodução dessas marcas ideológicas aglutinadas por esta centralidade modela e produz subjetividade, criando substratos para territórios nos quais o militante identitário encontra modos de existência baseados na exclusão da diferença. O centralismo constitui-se, portanto, no conjunto de estratégias de poder que são, ao mesmo tempo, expressão e reprodução da militância identitária, a qual, por sua vez, aciona mecanismos de reprodução dos centralismos existentes, assim como possibilita a criação de novos centralismos.

As formas autoritárias de militância seguem presentes, convivendo, é bem verdade, com outros modos de agir mais dialógicos, conforme nos mostra a história recente de nosso país, com os exemplos de construção cotidiana, firme e paciente de novas práticas que se aceleram a partir de meados da década de 1970. Esta militância, porém, também nasce fundada nas mesmas raízes da anterior, qual seja a afirmação de um indivíduo, de um sujeito identitário que se coloca enquanto "o Homem" (Benevides, Passos, 2005, p.568). Todavia, muitas vezes, busca estratégias para se desviar das práticas autoritárias e afirmar uma resistência à própria base identitária que a origina.

No campo da saúde, os centralismos e estas modelações identitárias se manifestam de distintas maneiras. Dentre elas destacamos: 1 - o "bem comum" em suas representações; 2 - o procedimento como oferta de tecnologias de saúde; 3 - o usuário e as concepções sobre suas necessidades/demandas, 
e 4 - a proteção inadvertida da vida. Temas que não são estranhos aos atuais debates a respeito dos desafios a uma Política Nacional de Humanização no SUS (PNH), conforme pudemos constatar no seminário "A humanização do SUS em debate", ocorrido em Vila Velha, ES, entre os dias 25 e 26 de junho de 2008. Essa contextualização se faz necessária para reafirmar nossa participação neste debate, organizado pela $\mathrm{PNH}$, enquanto um convite à pluralidade de interlocuções. Instigados por esse convite, partiremos da crítica aos centralismos aqui destacados, para propor uma outra militância no SUS.

\section{A problematização dos centralismos: apostando em desvios para a construção de uma nova militância no SUS}

Neste tópico levantaremos considerações sobre o que apontamos como centralismos produzidos e produtores da militância identitária. Na defesa do referencial ético-político do SUS, a questão não se trata de qual é a melhor militância. Faz-se necessário problematizar a construção identitária na militância no SUS, trazer visibilidade às estratégias inscritas nesses movimentos, objetivando apontar caminhos para uma nova possibilidade de militância.

Pontuamos a necessidade de se problematizar a noção de "bem comum" tantas vezes colocada como referência para a militância no SUS. Militar no SUS para o "bem comum", dependendo de qual definição deste é tomada, pode se constituir em uma das formas de centralismo que aqui combatemos. Um "bem comum" que se aproxima de uma forma de senso comum opera em uma reprodução da conformação atual e hegemônica da produção de subjetividades, configurando-se em uma produção capitalística do desejo (Guattari, Rolnik, 2005).

Buscando desvios, poderíamos utilizar a noção de comum segundo a definição de Hardt e Negri (2006). Para estes autores, o comum se constitui no próprio movimento de construí-lo. Menos um comum a priori, e mais um agir comum. Esse agir comum está relacionado à ampliação das fronteiras do possível, ao aumento de potencial em um encontro entre corpos, cujo efeito é a criação de modos de vida. É no sentido de que somos muito diferentes, que precisamos construir algo em comum para estarmos juntos e depois desfazê-lo, reconstruí-lo, e assim por diante. Este comum não implica afirmar uma forma de vida particular, mas as suas múltiplas formas e possibilidades, uma vida na qual o importante é como se vive. Para tanto o militante que se ocupa em dar passagem a modos não prescritivos de relação, amplia as possibilidades de construção do comum na convivência com a diferença. É, portanto, na dimensão relacional que se afirma e opera uma ética-militância/militânciaética para a construção do agir comum. Uma ética a ser produzida nos encontros, nos interstícios, no entre das relações - junto às forças que (i)mobilizam as ações, os afetos - portanto, uma ética do entre, uma militância do entre.

Mergulhando na distinção que trazemos dessa idéia de comum, destacamos sua contribuição para problematizar, na temática das políticas públicas universais, qual sentido dar ao enunciado constitucional do SUS, que afirma "a Saúde é direito de todos e dever do estado" (Brasil, 1988). Em uma militância do entre, será preciso cuidar para que o 'todos' não assuma um caráter homogeneizante, no qual é produzido um SUS que se pauta por um ideal de igual para todos, a partir de uma forma de consenso construído no movimento incessante de exclusão da diferença. Afirmamos que essa estratégia de cuidado não passa apenas pela intencionalidade da construção de consensos, mas também pela possibilidade de fazer emergir, de forma produtiva, os dissensos. Incluir o dissenso para ampliar as possibilidades de emergência das singularidades, enquanto uma direção na produção de subjetividades. Os consensos necessários demandam, ao mesmo tempo, uma duração que os façam produtivos e uma transitoriedade que não anule as diferenças neles contidas. É neste processo que se pretende fazer do SUS uma política pública universal que supere uma idealização homogeneizante do que se pretende que seja o usuário, e passe a dar conta de incluir o usuário que existe - seja ele branco, negro, transexual, morador de rua, rico ou pobre ou qualquer outra denominação que se possa rotular sobre alguém que vive no mundo.

O desafio posto às racionalidades gerenciais, quando assumem, como missão, responder às necessidades de saúde dos usuários do SUS, traduz-se no bom empenho do recurso público. 
Antecipam-se e priorizam-se tais necessidades e como as mesmas serão respondidas. No cotidiano dos serviços criam-se programas, equipamentos e protocolos com base nas representações que os usuários trazem do que sejam seus problemas de saúde. O modo de operar procedimento-centrado já antecipa, aos trabalhadores, aos gestores e aos usuários, um agir específico em que, na maioria das vezes, não se produz o dissenso necessário à construção de ferramentas para o trabalho, mas sim um dissenso baseado em angústias e queixas que produzem uma linguagem caótica, a qual impede esses atores de se entenderem e, até mesmo, se escutarem. E assim, o dissenso torna-se o centro do problema, e não o contrário. Deste modo, a racionalidade gerencial, que confia todas as suas fichas na padronização dos procedimentos, tenta ignorar ou subordinar o cotidiano de constante estranhamento e desvio que as relações impõem às práticas de saúde, na busca de um modo seguro e previsível de funcionamento dos serviços. A questão aqui não é a desvalorização dos procedimentos, mas quais efeitos essa antecipação pode produzir nos trabalhadores, nos gestores e, também, nos usuários, uma vez que esse modo de operar dificulta a visibilidade das produções subjetivas nos encontros.

Ao considerar-se a produção de saúde como produção de subjetividades, revela-se, no cotidiano dos serviços, a necessidade de se explodir a rigidez inerente a qualquer padronização. Neste caminho abrem-se possibilidades para a superação de situações típicas de muitos dos serviços, nas quais o usuário mostra seus sintomas e encontra uma resposta pré-formatada por parte de técnicos enquanto um modo operante que protege estes últimos do esforço de abrir-se ao encontro com o outro. Nesse regime, fica muito claro que não há condições de encontro entre profissionais e usuários, pois tal procedimento ou conduta está atravessado pelo poder enquanto instituinte do desencontro. É nesse território que o movimento de uma nova militância no SUS pode abrir-se para processos que se ocupem, efetivamente, da inclusão do dissenso como força motriz para a invenção de novos problemas, não com o objetivo de aniquilar a padronização dos procedimentos, mas produzir sua modulação na emergência das singularidades. Por essa razão, torna-se necessário, também, problematizar o pensamento e as práticas que procuram responder ao centralismo nos procedimentos, contrapondo a este outro polo: o centralismo no usuário.

Vemos que alguns dos gestores do SUS justificam todo o tipo de subordinação do trabalhador baseados em uma visão naturalizada do que seja "responder às demandas da população usuária". Em nome da "carência" da população, do "direito" do usuário à saúde, justifica-se todo tipo de autoritarismo e de precarização nas relações de trabalho. De acordo com Bauman, (2000), a precariedade é a característica mais difundida nas condições de trabalho na contemporaneidade. Ela pode ser entendida como uma experiência combinada de falta de garantias no trabalho (posição, títulos e sobrevivência), da incerteza (em relação à sua continuidade e à estabilidade futura) e de insegurança (do corpo, do eu e de suas extensões: posses, vizinhança e comunidade). Ouvimos muito que o SUS serve como um dos exemplos mundiais pela quantidade de ações desenvolvidas com recursos mínimos, o que, constantemente, gera o sofrimento de quem atua na área da saúde. Inevitavelmente, os trabalhadores se veem pressionados e criam linhas de fuga para sobreviverem a tal ritmo de trabalho. Não se pode ignorar que, simplesmente responder à "demanda", sem uma problematização, entre trabalhadores, gestores e usuários, do que seja e do que se legitima como demanda, significa, frequentemente, uma forma de submeter o trabalho em saúde no SUS à ordem capitalística de produção de subjetividades.

Fazer dos serviços de saúde "unidades de porta aberta" sem criar condições concretas para que as equipes dialoguem com essa demanda, configura-se também em uso inadequado dos recursos públicos. Isso pode significar a repetição de práticas travestidas de novos discursos sobre uma clínica degradada do tipo "queixa-conduta" (Campos, 2003; Gonçalves, 1994). Por exemplo, implantar o acolhimento como diretriz pode ser uma forma de estruturar um conjunto de procedimentos que pretende controlar e definir os modos de acesso e de relação das equipes com a "demanda".

Acolhimento sim, mas não como aquela repetição. Como afirmação de dispositivos que disparem novas subjetividades, outros modos de gestão (Merhy, 1994). Produção do acolhimento pensado como processo que oportuniza o cuidado com a relação trabalhador-usuário; como analisador das maneiras de se operar na clínica/gestão; como dispositivo que dispara algo que nos força a pensar em maneiras de fazer inovadoras. 
Discutir essas questões traz visibilidade à linha tênue que separa a defesa dos interesses dos usuários do controle dos seus modos de viver. E nos remete a problematizar outro centralismo: o ideal tão difundido de proteção da "vida". Uma vez que o militante, quando identificado com uma defesa intransigente da "vida", pode se tornar agente inadvertido de controle da mesma. A proteção da "vida", dessa forma, também tende a ser um centralismo. Será preciso perguntar ao militante no que consiste proteger a vida. Responder a essa questão não é fácil, sobretudo quando não se trata de um campo de idealidades. Não é suficiente tratar a "vida" apenas no seu sentido biológico ou moral. Será preciso saber quais modos de vida ajudamos a reproduzir enquanto agentes de uma política pública e quais formas de viver estão sendo extintas com essa interferência.

Foucault apontou para a crescente preocupação com a saúde da população. Em o Nascimento da Medicina Social (1999), sinaliza os efeitos de uma medicalização da vida e do espaço social, no qual os doentes tendem a perder o "direito sobre seu próprio corpo, o direito de viver, de estar doente, de se curar e morrer como quiserem" (p.96). Assim, a medicina, como um sistema de racionalização e de controle, invadiu o campo da saúde, expandindo a importância da doença. Ao proclamar o desejo de gerir a população, a medicina se torna uma instância normativa, um componente do biopoder. Em nome da saúde, constituiu-se uma nova moral, uma nova economia e uma nova política do corpo. Neste sentido, Foucault afirma que a vida se tornou o objeto das lutas políticas.

Os mecanismos institucionais de afirmação desse sistema de racionalização e de controle agem tanto para dar forma ao ato de cuidar, quanto para fazer com que seja atribuída, às tecnologias duras (Merhy, 1997), fundamental importância na formulação das respostas às necessidades dos usuários, fazendo da dimensão relacional do cuidado não só algo que deva ser esvaziado, mas, sobretudo, um obstáculo. Todavia, os conflitos vivenciados nessa dimensão relacional insistem em gerar ruídos que, quando tomados como analisadores, podem revelar, em sua virtualidade, a criação, a invenção de novas tecnologias de potencialização do sujeito, assim como a perpetuação das tecnologias de controle do mesmo. Toda tecnologia sempre está encarnada no corpo e este, em relação, é capaz de construir as linhas de fuga. É, portanto, nessa dimensão relacional, do entre, conforme já nos referimos, que uma nova militância pode agir.

Na vertente da biopolítica (Pelbart, 2003), quando acionamos o biológico em conjunto com sua potência agenciadora de afetos para a construção da vida, encontramos, talvez, uma saída legítima para a construção de uma clínica que atue nos processos de subjetivação (Carvalho, 2008). Uma clínica que demanda que a vida seja tomada como um movimento de produção de normas, e não de assujeitamento às mesmas. Passa, portanto, pela reinvenção da própria noção do humano e do homem que busca "menos a retomada ou revalorização da imagem idealizada do Homem e mais a incitação a um processo de produção de novos territórios existenciais" (Benevides, Passos, 2005, p.570).

O SUS enquanto uma política pública que pretende fugir da proposta neoliberal deve reconhecer, de antemão, o desafio que constitui, nos dias de hoje, o enfrentamento deste modo de produção. Deve também enfrentar, com especial vigor, a captura subjetiva que se realiza no interior da ordem social contemporânea (Carvalho, 2008), buscando imaginar e construir o que poderíamos ser para nos livrarmos deste "duplo constrangimento" político, que é a simultânea individualização e totalização próprias às estruturas de poder moderno, sendo, para isso, necessário " [...] lutar contra as formas de dominação (étnica, social e religiosa); contras as formas de exploração que separam os indivíduos daquilo que eles produzem; ou contra aquilo que liga o indivíduo a si mesmo e o submete, deste modo, aos outros" (Foucault, 1995, p.235).

É inerente ao projeto libertário do SUS repensar, dentro de suas práticas, estratégias que busquem romper com a imagem identitária e centralista que aqui problematizamos. É o que faz Teixeira (2003) quando propõe o exercício de uma clínica, de uma rede de conversações, que se afirma enquanto um ato cotidiano de afirmação democrática. 


\section{Considerações finais}

A militância do entre aposta no encontro entre trabalhadores, gestores e usuários como espaço para a produção da vida, da invenção de si e do mundo. No momento em que estes atores estão em relação emergem multiplicidades de agenciamentos que podem apontar para a produção de algo que vá para além daquilo que é denominado produção de saúde. Nesse entendimento, os saberes constituídos, as técnicas, as experiências, os conceitos, as crenças, as incertezas, o não-saber, enquanto forçasferramentas, podem se misturar constituindo máquinas disparadoras de produção de subjetividades. Desse modo, o militante do entre, considerando a produção de saúde como produção de subjetividades, não se exime e mergulha nessa dimensão, procurando causar desvios nessas produções. Todavia, esse mergulho não é fortuito, a intenção é mapear qual o movimento da criação dos encontros e agir na dimensão política dos mesmos. Passa pelo movimento de buscar pôr em cena os vários instrumentos e seus atores na produção coletiva da vida. Essa militância parte das relações (com o usuário, com a gestão, com o trabalho etc...) mapeando seus múltiplos nós e favorecendo novas conexões que vão mais na direção de uma rede de produção coletiva. A relação como conexão. É possível, assim, despersonificar a dor, o sofrimento e dar vazão à construção de um plano de relações que fuja da formatação da subjetividade e se abra para a emergência de um trabalho pautado na singularidade.

Mais do que contribuir para a construção de consciência crítica no militante, talvez o desafio atual seja o de afirmar a abertura para a incerteza. Correr riscos, e não, como muitos apontam, evitar o risco e deixar se congelar em uma vida repetitiva (Carvalho, 2004; Castiel, 2003).

Que tipo de militância queremos produzir? Uma militância do entre, uma ética da militância na qual não haja primazia do a priori. Uma militância entre os corpos, sejam esses corpos quais forem:

humanos, institucionais, históricos, virtuais... O que se pode sustentar em cada relação conforme o que se vive, e não tomando ideais como leis prescritivas.

O deslocamento do objeto da saúde em direção à relação-entre-sujeitos no lugar do objeto-sujeito e a afirmação da diferença e do dissenso para a construção de consensos transitórios e mutantes, constituem indicativos potentes para uma prática intensiva e micropolítica de produção de saúde e produção de novas subjetividades. Tarefa, portanto, clínica e política de mudar o mundo e de mudança de si.

\section{Colaboradores}

Os autores participaram igualmente da formulação, redação e revisões do texto.

\section{Referências}

BAUMAN, Z. Modernidade líquida. Rio de Janeiro: Jorge Zahar, 2000.

BENEVIDES, R.; PASSOS, E. A humanização como dimensão pública das políticas de saúde. Cienc. Saude Coletiva, v.10, n.3, p.561-71, 2005.

BRASIL. Nova Constituição da República Federativa do Brasil. São Paulo: Atlas, 1988.

CAMPOS, G.W.S. Por uma clínica reformulada e ampliada. In: Saúde Paidéia. São Paulo: Hucitec, 2003. p.51-67.

CARVALHO, S.R. Reflexões sobre o tema da cidadania e produção de subjetividade no SUS. Cienc. Saude Coletiva, 2008. (submetido à publicação) 
As contradições da promoção à saúde em relação à produção de sujeitos e a mudança social. Cienc. Saude Coletiva, v.9, n.3, p.669-78, 2004.

CASTIEL, L.D. Dédalo e os dédalos: identidade cultural, subjetividade e os riscos saúde. In CZERESNIA, D. (Org.). Promoção da saúde: conceitos, reflexões, tendência. Rio de Janeiro: Fiocruz, 2003. p.79-96.

FOUCAULT, M. O nascimento da Medicina Social. In: MACHADO, R. (Org.). Microfísica do poder. Rio de Janeiro: Graal, 1999. p.79-98.

Sujeito e poder. In: DREYFUS, H.L.; RABINOW, P. (Orgs.). Uma trajetória filosófica: para além do estruturalismo e da hermenêutica. Rio de Janeiro: Forense Universitária, 1995. p.231-49.

GONÇALVES, R.B.M. Tecnologia e organização das práticas de saúde: características tecnológicas do processo de trabalho na rede estadual de centros de saúde de São Paulo. São Paulo: Hucitec/Abrasco, 1994.

GUATTARI, F.; ROLNIK, S. Micropolítica: cartografia do desejo. Petrópolis: Vozes, 2005.

HARDT, M.; NEGRI, A. Multidão. Rio de Janeiro: Record, 2006.

MERHY, E. E. Em busca do tempo perdido: a micropolítica do trabalho vivo em saúde. In: ONOCKO, R.; MERHY, E.E. (Orgs.). Agir em saúde: um desafio para o público. São Paulo: Hucitec, 1997. p.71-112.

Em busca da qualidade dos serviços de Saúde: os serviços de porta aberta para a saúde e o modelo tecno-assistencial em defesa da vida. In: CECÍlIO, L.C.O. (Org.). Inventando a mudança na saúde. São Paulo: Hucitec, 1994. p.113-60.

NIETZSCHE, F. Genealogia da moral. São Paulo: Cia das Letras, 1998.

PELBART, P.P. Poder sobre a vida, potências da vida. In: Vida capital: ensaios de biopolítica. São Paulo: Iluminuras, 2003.

TEIXEIRA, R.R. O acolhimento num serviço de saúde entendido como rede de conversações. In: PINHEIRO, R.; MATTOS, R.A. (Orgs.). Construção da integralidade: cotidiano, saberes e práticas de saúde. Rio de Janeiro: UERJ, IMS, Abrasco, 2003.

OLIVEIRA, G.N. et al. Nuevas posibilidades de militancia en el crampo de la Salud: la afirmación de desvíos en los encuentros entre trabajadores, gestores y usuarios del Sistema Único de Salud Brasileño. Interface - Comunic., Saude, Educ., v.13, supl.1, p.523-9, 2009.

Los autores elaboran consideraciones sobre la militanoia en el campo de la salud, especialmente en defensa del Sistema Único de Salud (SUS) como política públioa universal. Tras presentar algunas estrategias de esta miliancia, el texto discute el centralismo y el caracter de identidad de estas prácticas. Destacan el conjunto de problemas de cuatro formas de centralismo: del "bien común" en sus representaciones; el procedimiento como oferta de tecnologías de salud; del usuario y los conceptos sobre sus necesidades/demandas; el de la protección inadvertida de la vida. Proponen como alternativa una nueva militancia en el SUS como práctica intensiva y producida en el encuentro, en dimensión nacional, entre gestores, trabajadores y usuarios.

Palabras clave: Sistema Único de Salud. Política de salud. Salud pública. Ética. Producción de subjetividad. 